\title{
Doenças do sistema digestório de caprinos e ovinos no semiárido do Brasil $^{1}$
}

\author{
Milena A. Aragão de Lira ${ }^{2 *}$, Sara Vilar D. Simões ${ }^{3}$, Franklin Riet-Correa ${ }^{3}$, Clarice \\ M.R. Pessoa ${ }^{2}$, Antônio Flávio M. Dantas ${ }^{3}$ e Eldinê G. Miranda Neto ${ }^{3}$
}

\begin{abstract}
Lira M.A.A., Simões S.V.D., Riet-Correa F., Pessoa C.M.R., Dantas A.F.M. \& Miranda Neto E.G. 2013. [Diseases of the digestive system of sheep and goats in the semiarid region of Brazil.] Doenças do sistema digestório de caprinos e ovinos no semiárido do Brasil. Pesquisa Veterinária Brasileira 33(2):193-198. Hospital Veterinário, Universidade Federal de Campina Grande, Campus de Patos, Avenida Universitária s/n, Patos, PB 58700000, Brazil. E-mail: aquilavet@yahoo.com.br

Diseases of the digestive system of goats and sheep in the semiarid region of northeastern Brazil were evaluated by a retrospective study of 2,144 attendances of small ruminants in the Veterinary Hospital of the Federal University of Campina Grande, Patos, Paraíba, from January 2000 to December 2011. The records were reviewed to determine the occurrence, epidemiology, and the main clinicopathological features of the gastrointestinal diseases diagnosed during the studied period. Out of a total of 512 cases $(23.9 \%)$ of gastrointestinal disorders in small ruminants, 367 (71.7\%) occurred in goats and 145 (28.1\%) in sheep. Gastrointestinal helminthiasis and coccidiosis were the most frequent diseases (330 cases). The disorders of the rumen and reticulum (acidosis, simple indigestion, bloat, and ruminal compaction) constituted 94 cases. The abomasum was affected by primary and secondary ulcers, and obstruction and compression of the gastrointestinal tract were also observed. Malformations, such as anal atresia and cleft palate were recorded in both species, the latter being associated with ingestion of Mimosa tenuiflora. Among the infectious diseases, five outbreaks of contagious ecthyma, two cases of paratuberculosis, and two cases of gastrointestinal pythiosis were observed. Suspected seven cases of enterotoxemia and nonspecific enteritis were identified. The lack of an integrated control of parasites and the use of inadequate food during the period of lack of forage contributes to the occurrence of a great number of gastrointestinal diseases in small ruminants in the studied area. The practice of conservation of fodder could substantially reduce the occurrence of digestive disorders in the semiarid region.
\end{abstract}

INDEX TERMS: Disease of goats and sheep, digestive system, semiarid Brazil.

RESUMO.- As doenças do sistema digestório de caprinos e ovinos na região semi-árida do nordeste do Brasil foram avaliadas através de um estudo retrospectivo de 2.144 atendimentos de pequenos ruminantes no Hospital Veterinário da Universidade Federal de Campina Grande, Patos, Paraíba, no período de janeiro de 2000 a dezembro de 2011. Os registros foram revisados para determinar a ocor-

\footnotetext{
${ }^{1}$ Recebido em 3 de outubro de 2012.

Aceito para publicação em 31 de dezembro de 2012.

${ }^{2}$ Programa de Pós-Graduação em Medicina Veterinária, Campus de Patos da Universidade Federal de Campina Grande (UFCG), Patos, PB 58700000, Brasil. *Autor para correspondência: aquilavet@yahoo.com.br

${ }^{3}$ Centro de Saúde e Tecnologia Rural (CSTR), Campus de Patos da UFCG, Patos, PB.
}

rência e as principais características clínicas, epidemiológicas e patológicas dessas enfermidades. De um total de 512 casos $(23,9 \%)$ de distúrbios digestivos, 367 (71,7\%) ocorreram em caprinos e 145 (28,3\%) em ovinos. As helmintoses gastrintestinais e a coccidiose foram as doenças mais frequentes, com um total de 330 casos. Os distúrbios da cavidade ruminoreticular (acidose, indigestão simples, timpanismo, e compactação ruminal) totalizaram 94 casos. 0 abomaso foi afetado primária e secundariamente por úlceras. Casos de obstrução e compressão do trato gastrointestinal também foram observados. Malformações como atresia anal e fenda palatina foram registradas em ambas as espécies, sendo esta última associada à ingestão de Mimosa tenuiflora. Entre as doenças infecciosas foram 
observados cinco casos de ectima contagioso, dois casos de paratuberculose e dois casos de pitiose gastrointestinal. Em sete animais suspeitou-se de enterotoxemia e 31 casos foram diagnosticados como enterite inespecífica. A não utilização de práticas de controle integrado de parasitas e a utilização de alimentos inadequados durante o período de escassez de forragem contribuiu para a ocorrência de um grande número de doenças. A prática de conservação de forragens poderia reduzir substancialmente a ocorrência de distúrbios digestivos na região semiárida.

TERMOS DE INDEXAÇÃO: Doenças de caprinos e ovinos, sistema digestório, semiárido do Brasil.

\section{INTRODUÇÃO}

Os distúrbios do sistema digestório em ruminantes abrangem um grupo de enfermidades importantes e são responsáveis por grandes perdas econômicas. A ocorrência destes distúrbios aumentou com a intensificação da produção e no período de escassez de forragens o uso de alimentos em quantidade ou qualidade inadequada leva também a transtornos digestivos e mortes.

No Brasil os distúrbios digestivos são mais frequentemente estudados em bovinos, sendo poucas as informações referentes aos pequenos ruminantes. Dessa forma, há a tendência de se considerar que a etiologia e patogenia dos distúrbios nessas espécies sejam semelhantes aos bovinos. No Brasil são identificados poucos estudos sobre transtornos digestivos em pequenos ruminantes e estes abordam principalmente a acidose ruminal. Estudos restrospectivos sobre a acidose ruminal em caprinos e em ovinos foram realizados, respectivamente, por Vieira et al. (2006) no Estado de Pernambuco e Silva et al. (2009) no Estado do Pará. Observa-se que também são escassos os trabalhos sobre as doenças infecciosas do sistema digestório sendo identificado apenas, um de enterotoxemia em caprinos (Colodel et al. 2003) e no Estado da Paraíba dois sobre paratuberculose (Oliveira et al. 2010, Medeiros et al. 2012) e um de ectima contagioso em caprinos e ovinos (Nóbrega Júnior et al. 2008).

Considerando a relativa escassez de estudos abordando aspectos clínicos e patológicos das enfermidades do sistema digestório de pequenos ruminantes, o objetivo deste trabalho foi relatar as enfermidades digestivas diagnosticadas nestas espécies no Hospital Veterinário (HV) da Universidade Federal de Campina Grande (UFCG) e descrever suas principais características epidemiológicas, clínicas e patológicas.

\section{MATERIAL E MÉTODOS}

Foram revistas as fichas clínicas dos pequenos ruminantes com afecções do sistema digestório atendidos no Ambulatório de Grandes Animais do Hospital Veterinário da Universidade Federal de Campina Grande (HV/UFCG) no período de janeiro de 2000 a dezembro de 2011. Nas fichas clínicas foram coletados dados referentes ao exame clínico, protocolo de tratamento e evolução dos casos.

Informações sobre os animais que morreram por afecções do sistema digestório foram também obtidas junto ao Laboratório de Patologia Animal (LPA) da UFCG. Fragmentos de órgãos dos animais encaminhados para necropsia foram fixados em formol tamponado a $10 \%$, processados rotineiramente para histologia, cortados em secções de $5 \mu \mathrm{m}$ e corados com hematoxilina e eosina.

Não foram consideradas neste estudo as intoxicações por plantas que causam distúrbios digestivos já relatadas por Medeiros et al. (2001), Nobre et al. (2005), Santos et al. (2007), Benício et al. (2007), Medeiros et al. (2009), Assis et al. (2009), Assis et al. (2010), Pessoa et al. (2010), Galiza et al. (2011), Riet-Correa et al. (2011) e Bezerra et al. (2012).

\section{RESULTADOS}

No período do estudo foram atendidos 2.144 pequenos ruminantes, sendo registrados 512 casos $(23,9 \%)$ de afecções digestivas. Dessas, 367 (71,7\%) foram diagnosticadas em caprinos e 145 (28,3\%) em ovinos. Foram registradas 193 mortes $(37,7 \%)$, sendo 131 em caprinos $(67,9 \%)$ e 62 em ovinos $(30,1 \%)$. As afecções diagnosticadas e a letalidade estão demonstradas no Quadro 1.

Quadro 1. Afecções do sistema digestório de caprinos e ovinos diagnosticadas no Hospital Veterinário da Universidade Federal de Campina Grande, Patos/PB, no período de janeiro de 2000 a dezembro de 2011

\begin{tabular}{lccccccc}
\hline \multicolumn{1}{c}{ Enfermidades } & \multicolumn{2}{c}{ Número } & Caprinos & \multicolumn{3}{c}{ Ovinos } & \multicolumn{2}{c}{ Letalidade } \\
& de Casos & N & $\%$ & N & $\%$ & N & $\%$ \\
\hline Helmintíases gastrintestinais & 272 & 193 & 70,9 & 79 & 29,1 & 90 & 33,1 \\
Acidose ruminal & 69 & 51 & 73,9 & 18 & 26,1 & 32 & 46,4 \\
Eimeriose & 58 & 39 & 67,2 & 19 & 32,8 & 15 & 25,9 \\
Malformações & 20 & 17 & 85 & 3 & 15 & 2 & \\
Enterite & 31 & 31 & 100 & - & - & 23 & 74,2 \\
Indigestão simples & 17 & 10 & 58,8 & 7 & 41,2 & 0 & - \\
Obstruções/compressões & 9 & 6 & 66,7 & 3 & 33,3 & 5 & 55,6 \\
Enterotoxemia & 7 & 5 & 71,5 & 2 & 28,5 & 7 & 100 \\
Ectima contagioso & 5 & 1 & 12,5 & 4 & 87,5 & 0 & - \\
Prolapso de reto & 5 & 2 & 40 & 3 & 60 & 2 & 40 \\
Compactação ruminal & 4 & 2 & 50 & 2 & 50 & 4 & 100 \\
Timpanismo & 4 & 4 & 100 & - & 0 & 2 & 50 \\
Hepatopatias & 4 & 2 & 50 & 2 & 50 & 4 & 100 \\
Úlcera de abomaso & 3 & 3 & 100 & - & 0 & 3 & 100 \\
Pitiose gastrintestinal & 2 & - & - & 2 & 100 & 2 & 100 \\
Paratuberculose & 2 & 1 & 50 & 1 & 50 & 2 & 100 \\
TOTAL & 512 & 367 & 71,7 & 145 & 28,3 & 193 & 37,7 \\
& & & & & &
\end{tabular}

As helmintíases gastrintestinais ocorreram na forma de surtos com alta mortalidade. 0 número de ovos por grama de fezes na espécie caprina foi em média 11.317 e na espécie ovina 9.861. Os ovos foram identificados como sendo nematódeos da superfamília Trichostrongylidae e dos gêneros Strongyloides spp. e Trichuris spp. e cestódeos do gênero Moniezia spp. 0 principal parasito responsável pela doença clínica foi o Haemonchus sp. Dos 272 animais com helmintíases gastrintestinais, 159 (58,45\%) eram provenientes de rebanhos em que a vermifugação era realizada rotineiramente sendo a principal, e às vezes, única forma de controle utilizada.

Dos 69 casos de acidose ruminal diagnosticados, 37 $(53,62 \%)$ ocorreram em animais adultos e 32 (46,37\%) em animais com idade inferior a um ano. Os animais mais frequentemente acometidos eram de pequenos produtores com pouco ou nenhum recurso forrageiro e que utilizavam alimentos como restos de comida caseira (lavagens) e de padaria, frutas e fontes de carboidrato de fácil digestão como milho em grãos e farelo de milho. Os sinais clínicos 
observados foram apatia, anorexia, desidratação, distensão abdominal, rúmen repleto de líquido, com hipomotilidade ou atonia ruminal e timpanismo leve. Bruxismo e gemidos foram observados nos casos mais graves estando estes sinais associados com prognóstico ruim. A diarreia não foi comum $(8,7 \%-6 / 69)$, porém foi observada nos casos em que o $\mathrm{pH}$ do fluido ruminal estava inferior a 5,0. A mortalidade foi alta nos animais severamente afetados 32/69 $(46,4 \%)$ sendo registrados 24 mortes óbitos em caprinos e 8 em ovinos.

Em 55 dos 69 casos de acidose se julgou possível realizar o tratamento clínico, que incluiu sifonagem, fluidoterapia parenteral nos casos mais graves, fluido ruminal (2l) e bicarbonato de sódio oral $(0,5 \mathrm{~g} / \mathrm{kg})$. Com este protocolo $37(67,3 \%)$ animais receberam alta e $19(34,5 \%)$ morreram. Dez animais $(19,23 \%)$, que apresentavam sinais clínicos mais graves ou $\mathrm{pH}$ inferior a 5,0 foram encaminhados para rumenotomia, dois se recuperaram $(20 \%)$ e oito $(80 \%)$ morreram.

$\mathrm{Na}$ necropsia na mucosa ruminal foram observadas áreas avermelhadas, espessadas e escurecidas. Papilas aumentadas de tamanho, principalmente no saco dorsal, desprendimento da mucosa e hiperemia da submucosa também foram visualizadas. No retículo e omaso também havia áreas avermelhadas na mucosa e escurecida na serosa, sendo visualizadas neste último áreas desnudas de papilas. Microscopicamente os achados mais frequentes foram vacuolização do citoplasma, formação de vesículas e pústulas, infiltrado inflamatório neutrofílico ou misto e dilatação de vasos na submucosa com desprendimento do epitélio. Em sete casos havia avermelhamento da mucosa do abomaso, áreas de erosões, úlceras do tipo I e equimoses. Em dois casos foram vistas lesões no duodeno sendo uma úlcera perfurante que resultou em peritonite em um ovino e múltiplas erosões em um caprino.

A eimeriose foi diagnosticada principalmente em caprinos leiteiros jovens, ocasionando alta taxa de mortalidade e grave comprometimento no desenvolvimento dos animais acometidos. Observou-se que esta enfermidade ocorre de forma endêmica nas propriedades e a reinfecção dos animais era frequente. 0 número de oocistos por grama de fezes entre os animais atendidos no HV variou de 6.000 a 587.400.

Processos compressivos e obstrutivos foram diagnosticados no trato gastrintestinal sendo quatro no esôfago, um no cárdia e quatro no intestino. As obstruções intestinais foram decorrentes de fitobenzoar (2), encarceramento (1) e torção de alças intestinais (1). Um dos casos de obstrução por fitobenzoar ocorreu em uma cabra que se alimentava de pastagem, algaroba (Prosopis juliflora), milho e grama. No exame clínico observou-se anorexia, ausência de ruminação, desconforto e aumento na tensão abdominal, abaulamento do flanco esquerdo e rúmen com conteúdo firme.

Os casos de compactação ruminal estiveram associados à ingestão de alimento fibroso com baixa digestibilidade e corpos estranhos como sacos plásticos descartados no meio ambiente e ingeridos pelos animais criados soltos em áreas urbanas e com acesso ao lixo. Os animais apresentaram estado nutricional ruim, apetite reduzido, desidrata- ção, palidez de mucosas, rúmen com conteúdo firme, hipomotílico e com timpanismo leve. As fezes eram escassas e cobertas de muco. Na análise do fluido ruminal observou-se pH 7,5, tempo de redução do azul de metileno maior que 10 minutos e ausência de infusórios. Em um dos animais o teor de cloretos estava em $51 \mathrm{mEq} / \mathrm{L}$ considerado elevado para os padrões normais da espécie $(\leq 30 \mathrm{mEq} / \mathrm{L})$. 0 tratamento realizado nos animais incluiu administração de sais laxantes (purgante salino) por via oral, fluidoterapia e transfaunação. Em dois animais foram realizadas ruminotomias e grande quantidade de sacos plásticos foram retirados. Os animais não responderam de forma satisfatória a intervenção cirúrgica e morreram, assim como os que foram tratados clinicamente. Na necropsia dos que não foram submetidos à rumenotomia também havia nos pré-estômagos sacos plásticos e material fibroso seco e compactado.

Em relação às afecções do abomaso três animais tiveram este órgão primariamente acometido com úlceras, que penetraram toda a mucosa e se estenderam pela submucosa, muscular externa e serosa. As úlceras foram classificadas como sendo do tipo IV e ocasionaram aderências entre diversos órgãos devido à peritonite difusa. Foi registrado um caso em caprino jovem, macho, com 6 dias de idade que se alimentava com leite. No exame físico apresentava mucosas congestas, desidratação, anorexia e diarreia. Os outros dois casos ocorreram em um macho adulto e uma fêmea que tinha parido há cinco dias e após o parto apresentou distensão abdominal, contrações abdominais e salivação. A alimentação dos animais adultos era variada, o macho tinha acesso somente a pasto nativo e a fêmea, além de pasto nativo, tinha acesso a capim andrequicé (Leersia hexandra) e concentrado.

Os casos de pitiose gastrointestinal ocorreram em ovinos com 15 e 30 dias de idade. 0 animal mais jovem apresentou anorexia, regurgitação, letargia e óbito cinco dias após apresentação dos sinais. 0 segundo animal não apresentava alterações digestivas e deu entrada no HV devido à fratura no terço média da tíbia. Os dois animais morreram e na necropsia os achados foram semelhantes. A mucosa do esôfago, pré-estômagos e abomaso tinham áreas ulceradas que se estendiam até a serosa. Aderências foram visualizadas entre a serosa dos pré-estômagos e abomaso e entre o fígado e o abomaso. As lesões histológicas mostraram inflamações piogranulomatosas transmurais necrosantes nos órgãos afetados e trombose vascular e hifas intralesionais. A presença de Pythium insidiosum foi confirmada por imuno-histoquímica e cultura.

\section{DISCUSSÃO}

A presença de sinais clínicos característicos como palidez de mucosas e edema submandibular e a presença de numerosos parasitas adultos no abomaso dos animais necropsiados demonstraram que o principal parasito dos caprinos e ovinos foi o Haemonchus sp. Outros estudos também identificaram que este é o principal gênero de parasito na região (Santa Rosa et al. 1986, Silva et al. 1998, Costa et al. 2011). Apesar de diversos estudos sobre parasitoses gastrintestinais dos pequenos ruminantes terem sido realizados na 
região semiárida do Brasil sendo estudadas as principais espécies de parasitos (Vieira et al. 1997, Martins Filho \& Menezes 2001), a resistência, sensibilidade e eficácia das drogas antihelmínticas (Rodrigues et al. 2007, Pereira et al. 2008, Melo et al. 2009, Lima et al. 2010) os aspectos epidemiológicos e formas de controle da enfermidades (Vieira et al. 2008, Pinto et al. 2008, Costa et al. 2011) as parasitoses continuam a ser um fator limitante para a caprinocultura conforme referenciado por Santos et al. (2011), Filgueira et al. (2009) e Bandeira et al. (2007). Na região semiárida, assim como em outras regiões do país, a realização de pesquisas abordando aspectos pontuais da enfermidade e principalmente a inexistência de estudos que avaliem efetivamente o controle integrado de parasitos são aspectos que fazem com que essa enfermidade continue sendo um dos mais sérios problemas sanitários da caprinovinocultura.

Ainda no contexto das parasitoses observou-se que, em animais jovens, a associação da infecção por nematódeos com a eimeriose ocasionava mortalidade em 100\%. Os animais que morreram eliminavam em média 6.250 OPG e 91.368 OOPG. No caso de infecção apenas com nematódeos (infecção média de 6.221 OPG) a mortalidade reduzia para $33,33 \%$. Nos sistemas produtivos da região observa-se que os animais jovens são submetidos a estresse dietético quando a maior parte do leite é comercializada e estes não recebem suporte nutricional. Esta situação é agravada na ocasião do desmame e frequentemente são observados surtos de eimeriose. De acordo com Radostits et al. (2002) o estresse dietético pode predispor à eimeriose. Outro aspecto que deve ser considerado na epidemiologia desta enfermidade é o surgimento de sistemas de produção de leite caprino sem a implantação de tecnologias e práticas de manejo necessárias às formas intensivas de criação.

Ao se considerar todos os distúrbios da cavidade ruminorreticular, que incluíram casos de acidose ruminal, indigestões simples, compactação ruminal e timpanismo observa-se que esses estão associados a erros alimentares devido a escassez de forragens. A acidose foi a enfermidade com maior mortalidade e em pequenos ruminantes o tratamento clínico mostrou-se mais satisfatório que a intervenção cirúrgica. Resultados semelhantes foram obtidos por Vieira et al. (2006) que identificaram maior taxa de recuperação em animais submetidos ao tratamento clínico. Na necropsia as lesões macro e microscópicas, identificadas nos pré-estômagos e abomaso, demonstraram a ocorrência de processos de ruminite e gastrite química semelhantes aos descritos na literatura (Jensen \& Mackey 1974, Radostits et al. 2002, Maxie 2007, MacGavin \& Zachary 2009).

O exame clínico e a avaliação dos infusórios do suco ruminal foram recursos utilizados para diferenciar a indigestão simples da acidose ruminal, considerando que a epidemiologia das duas enfermidades é semelhante e em alguns casos de acidose o $\mathrm{pH}$ se encontrava dentro da normalidade. Havendo infusórios, apenas em quantidade e motilidade diminuída, e não sendo observados sinais clínicos de bruxismo, decúbito e gemidos, considerados importantes na acidose em pequenos ruminantes, o caso era diagnosticado como indigestão simples. As indigestões simples geralmente não necessitam de tratamento e são autolimi- tantes, porém na rotina do HV observou-se que a retirada de parte do conteúdo ruminal por sifonagem, fluidoterapia oral e suco de rúmen abreviava o tempo de duração da enfermidade.

Nos casos de compactação ruminal as alterações observadas no suco ruminal foram associadas à ingestão de alimentos de má qualidade e a anorexia. De acordo com Afonso \& Borges (2007) e Vanitha et al. (2010) a deficiência de nutrientes necessários para o ativo crescimento microbiano reduz as populações microbianas, compromete os processos fermentativos e modifica a dinâmica do rúmen ocasionando acúmulo de alimento nos pré-estômagos e/ou no abomaso. De acordo com Nwity \& Chaudhry (1995) a compactação ruminal pode ser causada pela alimentação prolongada de dietas com baixa energia, alto teor de fibras, dieta composta por volumosos secos ou feno de capim de baixa qualidade. Esta situação epidemiológica é vista frequentemente no semiárido. A elevação do teor de cloretos observada no suco ruminal de um dos animais com compactação ruminal sugere refluxo de conteúdo do abomaso, que geralmente ocorre quando existe obstrução no abomaso ou distal ao mesmo (Rings et al. 1984). A presença de aderências entre retículo e diafragma, observada neste animal por ocasião da necropsia, sugere que a compactação foi decorrente de distúrbios motores semelhantes aos observados na indigestão vagal em bovinos.

Em relação às obstruções intestinais observou-se que apesar de não serem frequentes em pequenos ruminantes (Navarre \& Pugh 2004) devem ser consideradas no diagnóstico diferencial das enfermidades do trato digestório nessas espécies. A baixa frequência de casos leva o clínico a não considerá-las no diagnóstico diferencial o que pode ser comprovado neste estudo, pois os quatro casos foram diagnosticados apenas no momento da necropsia. De acordo com Fraser et al. (1996) alimentos fibrosos podem levar a formação de fecaloma, e a intussuscepção e o vólvulo podem ocorrer, entre outras causas, devido a movimentos peristálticos irregulares associados à enterite e parasitismo intestinal.

0 diagnóstico da forma aguda da enterotoxemia, dado através dos sinais clínicos e achados patológicos, demonstra a necessidade de se estabelecer medidas adequadas de prevenção desta enfermidade especialmente para a espécie caprina, na qual os procedimentos de imunização devem ser realizados com intervalos mínimo de 4 meses em rebanhos com histórico da doença (Smith e Sherman 2009). Casos subagudos também têm sido diagnosticados na região (Pimentel et al. 2010, Oliveira et al. 2010).

Os graves casos de úlcera abomasal que foram diagnosticados não tiveram sua etiologia definida, porém os animais acometidos foram submetidos a algumas condições predisponentes referenciadas na literatura como alta inclusão de concentrado na dieta, condições estressantes como desmame, transporte, parto e doenças intercorrentes (Aukema \& Breukink 1974, Anderson et al. 1992). 0 fornecimento de substituto de leite à vontade e trauma na mucosa devido a adição de alimento grosseiro também são considerados fatores predisponentes (Marshall 2009). As úlceras de abomaso são afecções pouco relatadas em pequenos ruminantes no Brasil (Biscarde et al. 2011). 
As infecções fúngicas são enfermidades importantes na região semiárida, pois surtos de pitiose cutânea (Tabosa et al. 2004) e rinites (Portela et al. 2010) já foram diagnosticados em ovinos que pastejavam em margens de açudes. Os casos de pitiose gastrintestinal também ocorreram em áreas onde os animais tinham acesso a açudes demonstrando que a infecção pode ocorrer em diversos sistemas orgânicos e que a presença de umidade é uma condição epidemiológica importante.

Em relação a paratuberculose observa-se que esta enfermidade vem sendo diagnosticada na região e que, devido ao fato dos animais acometidos apresentarem sinais clínicos semelhantes aos das parasitoses gastrintestinais, o produtor realiza erroneamente repetidas vermifugações na tentativa de solucionar o problema. 0 desconhecimento da enfermidade faz com que os animais acometidos fiquem muito tempo nas propriedades, favorecendo a infecção de novos animais. Estudos sobre a paratuberculose foram realizados na região por Oliveira et al. (2010) e Medeiros et al. (2012).

\section{CONCLUSÕES}

As afecções do sistema digestório representam uma parcela considerável das enfermidades de caprinos e ovinos na região semiárida e apresentam alta morbidade e letalidade ocasionando graves perdas econômicas.

A escassez e a não utilização de práticas de conservação de forragens estão associadas a maioria dos transtornos digestivos.

Observa-se que enfermidades que não são diagnosticadas com frequência como compactação ruminal, úlceras de abomaso, obstruções intestinais, pitiose gastrintestinal e paratuberculose devem ser consideradas no diagnóstico diferencial das enfermidades do trato gastrintestinal de pequenos ruminantes.

\section{REFERÊNCIAS}

Afonso J.A.B. \& Borges J.R.J. 2007. Compactação de rúmen, p.319-322. In: Riet-Correa F., Schild A.L., Lemos R.A.A. \& Borges J.R.J. (Eds), Doenças de Ruminantes e Equídeos. Vol.2. $3^{\text {a }}$ ed. Palloti, Santa Maria.

Anderson N.V., Sherding R.G., Merritt A.M. \& Whitlock R.H. 1992. The stomachs and fore-stomachs, p.721-751. In: Anderson N.V. (Ed.), Veterinary Gastroenterology. ${ }^{\text {nd }}$ ed Lea and Febiger, Philadelphia.

Assis T.S., Medeiros R.M.T., Araújo J.A.S., Dantas A.F.M. \& Riet-Correa F. 2009. Intoxicações por plantas em ruminantes e equídeos no Sertão Paraibano. Pesq. Vet. Bras. 29(11):919-924.

Assis T.S., Medeiros R.M.T., Riet-Correa F., Galiza G.J.N., Dantas A.F.M. \& Oliveira D.M. 2010. Intoxicações por plantas diagnosticadas em ruminantes e equinos e estimativa das perdas econômicas na Paraíba. Pesq. Vet. Bras. 30(1):13-20.

Aukema J.J. \& Breukink H.J. 1974. Abomasal ulcer in adult cattle with fatal hemorrhage. Cornell Vet. 64:303-317.

Bandeira D.A., Castro R.S., Azevedo E.O., Melo L.S.S. \& Melo C.B. 2007. Perfil sanitário e zootécnico de rebanhos caprinos nas microrregiões do Cariri paraibano. Arq. Bras. Med. Vet. e Zootec. 59(6):597-600.

Benício T.M.A., Nardelli M.J., Nogueira F.R.B., Araújo J.A.S. \& Riet-Correa F. 2007. Intoxication by the pods of Enterolobium contortisiliquum in goats, p.514519. In: Panter K.E., Wirenga T.L. \& Pfister J.A. (Eds), Poisonous Plants: Global research and solutions. CABI Publishing, Wallingford, Oxon, UK.

Bezerra C.W.C., Medeiros R.M.T., Rivero B.Riet-Correa, Dantas A.F.M. \& Riet-Correa F.A. 2012. Plantas tóxicas para ruminantes e equídeos da microrregião do Cariri Cearense. Ciênc. Rural. 42(6):1070-1076.
Biscarde C.E.A., Carvalho V.S. \& Rodello L. 2011. Úlcera de abomaso em pequenos ruminantes. Disponível em: <http://www.farmpoint.com.br/ radares-tecnicos>. Acesso em 10 abril 2012.

Colodel E.M., Driemeier D., Schmitz M., Germer M., Nascimento R.A.P., Assis R.A., Lobato F.C.F. \& Uzal F.A. 2003. Enterotoxemia em caprinos no Rio Grande do Sul. Pesq. Vet. Bras. 23:173-178.

Costa V.M.M., Simões S.V.D. \& Riet-Correa F. 2011. Controle das parasitoses gastrintestinais em ovinos e caprinos na região semiárida do Nordeste do Brasil. Pesq. Vet. Bras. 31(1):65-71.

Filgueira T.M.B., Ahid S.M.M., Suassuna A.C.D., Souza W.J. \& Fonseca Z.A.A.S. 2009. Aspectos epidemiológicos e sanitários das criações de caprinos na região da Chapada do Apodi. Revta. Verde Agroec. Desenv. Sust. 4(2):64-67.

Fraser M.C., Bergeron J.A., Mays A. \& Aiello S.E. 1996. Manual Merck de Veterinária: Um manual de diagnóstico, tratamento, prevenção e controle de doenças para o veterinário. 7ª ed. Roca, São Paulo, p.193-195.

Galiza G.J.N., Luciano A.P., Oliveira D.M., Pierezan F., Dantas A.F.M., Medeiros R.M.T. \& Riet-Correa F. 2011. Intoxicação por Portulaca elatior (Portulacaceae) em caprinos. Pesq. Vet. Bras. 31(6):465-470.

Jensen R. \& Mackey D.R. 1974. Diseases of Feedlot Cattle. Lea and Febiger, Philadelphia. 377p.

Lima W.C., Athayde A.C.R., Medeiros G.R., Lima D.A.S.D., Borburema J.B., Santos E.S., Vilela V.L.R. \& Azevedo S.S. 2010. Nematóides resistentes a alguns anti-helmínticos em rebanhos caprinos no Cariri Paraibano. Pesq. Vet. Bras. 30(12):1003-1009.

Marshall T.S. 2009. Abomasal ulceration and tympany of calves. Vet. Clin. Food Anim. 25:209-220.

Martins Filho \& Menezes R.C.A.A. 2001. Parasitos gastrintestinais em caprino (Capra hircus) de uma criação extensiva na microrregião de Curimataú, Estado da Paraíba, Brasil. Pesq. Vet. Bras. 10(1):41-44.

Maxie M.G. 2007. Jubb, Kennedy \& Palmer's Pathology of Domestic Animals. Vol.2. ${ }^{\text {th }}$ ed. W.B. Saunders Elsevier, Philadelphia. 771p.

McGavin M.D. \& Zachary J.F. 2009. Pathologic Basisc of Veterinary. $4^{\text {th }}$ ed. Mosby Elsevier. 1476p.

Medeiros R.M.T., Barbosa R.C., Lima E.F., Simões S.V.S. \& Riet-Correa F.A. 2001. Intoxication by Plunbago scadens in goats in Paraíba, northeastern Brazil. Vet. Hum. Toxicol. 43(3):167-169.

Medeiros R.M.T., Yassaki J.K.M., Araújo J.A., Dantas A.F.M. \& Riet-Correa F.A. 2009. Poisoning by Centraterum brachylepis in ruminants. Toxicon 54(1):77-79.

Medeiros J.M.A., Garino Junior F., Almeida A.P., Lucena E.A. \& Riet-Correa F. 2012. Paratuberculose em caprinos e ovinos no Estado da Paraíba. Pesq. Vet. Bras. 32(2):111-115.

Melo A.C.F.L., Bevilaqua C.M.L. \& Reis I.F. 2009. Resistência aos anti-helmínticos benzimidazóis em nematóides gastrintestinais de pequenos ruminantes do semiárido nordestino brasileiro. Ciênc. Anim. Bras. 10(1):294-300.

Navarre C.B. \& Pugh D.G. 2004. Timpanismo, p.82-83. In: Pugh D.G. (Ed.), Clínica de Ovinos e Caprinos. Roca, São Paulo.

Nobre V.M.T., Dantas A.F.M., Riet-Correa F., Barbosa Filho J.M., Tabosa I.M. \& Vasconcelos J.S.V. 2005. Acute intoxication by Crotalaria retusa in sheep. Toxicon 45:347-352.

Nóbrega Júnior J.E., Macêdo J.T.S.A., Araújo J.A.S., Dantas A.F.M., Soares M.P. \& Riet-Correa F. 2008. Ectima contagioso em ovinos e caprinos no semi-árido da Paraíba. Pesq. Vet. Bras. 28(1):135-139.

Nwity T.B.E. \& Chaudhry S.U.R. 1995. Ruminal impactation due to indigestible materials in arid zone of Borno State of Nigeria. Pakistan Vet. J. 15(1):29-33.

Oliveira D.M., Riet-Correa F., Galiza G.J.N., Assis A.C.O., Dantas A.F.M., Bandarra P.M. \& Garino Júnior F. 2010. Paratuberculose em caprinos e ovinos no Brasil. Pesq. Vet. Bras. 30(1):67-72.

Oliveira D.M., Pimentel L.A., Pessoa A.F., Dantas A.F.M., Uzal F. \& Riet-Correa F. 2010. Focal symmetrical encephalomalacia in a goat. J. Vet. Diagn. Invest. 22:793-796.

Pereira R.H.M.A., Ahid S.M.M., Bezerra A.C.D.S., Soares H.S. \& Fonseca 
Z.A.A.S. 2008. Diagnóstico da resistência dos nematóides gastrintestinais a anti-helmínticos em rebanhos caprino e ovino do RN. Acta Vet. Bras. 2(1):16-19.

Pessoa C.R.M., Medeiros R.M.T., Pessoa A.F.A., Araújo J.A., Dantas A.F.M., Silva-Castro M.M. \& Riet-Correa F. 2010. Diarréia em caprinos associada ao consumo de Arrabidaea corallina (Bignoniaceae). Pesq. Vet. Bras. 30(7):547-550.

Pimentel L.A., Oliveira D.M., Galiza G.J.N., Dantas A.F.M., Uzal F. \& Riet-Correa F. 2010. Focal symmetrical encephalomalacia in sheep. Pesq. Vet. Bras. 30(5):423-427.

Pinto J.M., Oliveira M.A., Alvares C.T., Costa-Dias R. \& Santos M.H. 2008. Relação entre o periparto e a eliminação de ovos de nematóides gastrintestinais em cabras Anglo Nubiana naturalmente infectadas em sistema semi-extensivo de produção. Revta Bras. Paras. Vet. 17(1):138143.

Portela R.A., Riet-Correa F., Garino Júnior F., Dantas A.F.M., Simões S.V.D. \& Silva S.M.S. 2010. Doenças da cavidade nasal em ruminantes no Brasil. Pesq. Vet. Bras. 30(10):844-854.

Radostits O.M., Gay C.C., Blood D.C. \& Hinchcliff K.W. 2002. Clínica Veterinária: um tratado de doenças dos bovinos, ovinos, suínos, caprinos e eqüinos. 9a ed. Guanabara Koogan, Rio de Janeiro, p.1163-1171.

Riet-Correa F., Carvalho K.S., Dantas A.F.M. \& Medeiros R.M.T. 2011. Spontaneous acute poisoning by Crotalaria retusa in sheep and biological control of this plant with sheep. Toxicon 58:606-609.

Rings D.M., Welker F.H. \& Kersting K.W. 1984. Abomasal emptying detect in Suffolk sheep. J. Am. Vet. Med. Assoc. 185(12):1520-1522.

Rodrigues S.A.B., Athayde A.C.R., Rodrigues O.G., Silva W.W. \& Faria E.B. 2007. Sensibilidade dos nematóides gastrintestinais de caprinos a antihelmínticos na mesorregião do Sertão Paraibano. Pesq. Vet. Bras. 27(4): 162-166.

Santa Rosa J., Berne M.E., Johnson E. \& Olander H.J. 1986. Doenças de caprinos diagnosticadas em Sobral, Ceará. Anais da Reunião Técnica do Programa de Apoio à Pesquisa Colaborativa de Pequenos Ruminantes, Sobral, vol.1. Embrapa-CNPC, p.235-241.

Santos J.C., Riet-Correa F., Dantas A.F.M., Barros S.S., Molyneux R.J., Medei- ros R.M.T., Silva D.M. \& Oliveira O.F. 2007. Toxic hepatopathy in sheep associated with the ingestion of the legume Tephrosia cinerea. J. Vet. Diag. Invest. 19:690-694.

Santos T.C.P., Alfaro C.E.P. \& Figueiredo S.M.A. 2011. Aspectos sanitários e de manejo em criações de caprinos e ovinos na microrregião de Patos, Região semiárida da Paraíba. Ciênc. Anim. Bras. 12(2):206-212.

Silva W.W., Bevilaqua C.M.L. \& Costa A.L. 1998. Natural evolution of gastrointestinal nematodes in goats (Capra hircus) in the semiarid ecosystem of the Paraíba backwoods, northeastern Brazil. Vet. Parasitol. 80:47-52.

Silva N.S., Silveira J.A.S., Campos K.F., Sousa M.G.S., Lopes C.T.A., Oliveira C.M.C., Duarte M.D. \& Barbosa J.D. 2009. Acidose ruminal em ovinos, diagnosticada pela Central de Diagnóstico Veterinário (Cedivet) da Universidade Federal do Pará, no período de 2000 a 2008. Anais VIII Congresso Brasileiro de Buiatria, Belo Horizonte, MG. Ciência Animal Brasileira. 1:1-6. (Resumo)

Smith M.C. \& Sherman D.M. 2009. Goat Medicine. $2^{\text {th }}$ ed. Wiley-Blackwell, John Wiley and Sons Publication, USA. 406-412p.

Vanitha V., Nambi A.P., Gowri B. \& Kavitha S. 2010. Rumen impactation in cattle with indigestible foreign bodies in Chennai. Tamilnadu. J. Vet. Anim. Sci. 6(3):138-140.

Vieira L.S., Cavalcante A.G.R. \& Ximenes L.J.F. 1997. Epidemiologia e controle das principais parasitoses de caprinos nas regiões semiáridas do Nordeste do Brasil. Circ. Téc., Embrapa Caprinos, Sobral. 49p.

Vieira A.C.S., Afonso J.A.B., Mendonça C.L., Costa N.A. \& Sousa M.I. 2006. Estudo retrospectivo da acidose láctica em caprinos e ovinos atendidos na Clínica de Bovinos, Campus Garanhuns/ UFPE. Revta Bras. Ciênc. Agrárias 1(1):97-101.

Vieira L.S. 2008. Métodos alternativos de controle de nematóides gastrintestinais em caprinos e ovinos. Tecnol. \& Ciên. Agropec. 2(2):49-56.

Uzal F.A. \& Kelly W.R. 1999. Serum antibody responses to a Clostridium perfringens epsilon toxóide vaccine in goats. Anaerobe 5:287-289.

Tabosa J.M., Riet-Correa F., Nobre V.M.TE., Azevedo O., Reis-Júnior J.L. \& Medeiros R.M.T. 2004. Outbreaks of pythiosis in two flocks of sheep in northeastern Brazil. Vet. Pathol. 41:412. 